\title{
Perfil do diretor da escola pública estadual paulista
}

\author{
Profile of the paulista public school principal
}

\author{
Viviani Fernanda Hojas* \\ Universidade Estadual Paulista \\ Graziela Zambão Abdian** \\ Universidade Estadual Paulista
}

Resumo O objetivo deste texto foi analisar o perfil do diretor de escola pública paulista, problematizando a literatura da área, os concursos públicos e as diretrizes da política. As constatações permitiram-nos afirmar que, apesar do avanço dos anos 1980, sobremaneira no que diz respeito à negação da Administração empresarial e ao incentivo para a construção de um corpo teórico próprio para a Administração escolar, o que predomina nos anos mais recentes é a não formação inicial do diretor de escola e uma atuação baseada no "manager". Os avanços conquistados encontram barreiras reais quando este diretor concursado é submetido aos cursos de formação continuada e às legislações que determinam um perfil gerencial, os quais não dialogam com uma formação inicial fortalecida e alternativa ao que recebe, quase diariamente, das instâncias superiores.

PalaVRas-Chave: Diretor de escola pública, Produção teórica em Administração escolar, Política educacional paulista.

Abstract The aim of this paper was to analyze the possible profile (s) of the of the paulista public school principal, questioning the literature in the area, public service exams and policy guidelines, ambos from the state, in a historical perspective. The findings allowed us to state that, despite advances in the 1980s, mainly regarding the denial of business Administration and the incentive for the construction of a theoretical body proper to school Administration, what predominates in more recent years is the non-initial training of the school principal and a performance based on the "manager". The achieved advances found real (and pragmatic) barriers when this examined principal is submitted to continued training courses and to legislation that determine a managerial profile, emptied of other possibilities for not dialoguing with an alternative strengthened initial training regarding what is received daily from higher courts.

KEYWORDS: Public School Principal, Theoretical Production in School Administration, Paulista Educational Policy. 


\section{Introdução}

Neste texto, apresentamos resultados do desenvolvimento de projeto integrado de pesquisa, o qual reuniu diferentes pesquisadores, com o apoio financeiro da Fundação de Amparo à Pesquisa do Estado de São Paulo (FAPESP). Tal projeto teve como objetivos principais: a) analisar questões históricas e atuais relacionadas à formação, função e provimento do cargo do gestor escolar e suas possíveis implicações na qualidade de ensino da escola pública; b) problematizar a literatura da área, no que se refere às temáticas articuladas, tensionando-a com as propostas e práticas de Gestão da educação. A pesquisa envolveu vários subprojetos com temáticas integradas ao objetivo principal e utilizou diferentes procedimentos de coleta de dados.

Para a construção deste texto, especificamente, consideramos diferentes âmbitos de análise (legislação nacional e paulista, editais de concursos, produção teórica da área) e nos detivemos às questões seguintes: é possível delimitar um perfil do diretor de escola pública estadual paulista? Como os autores que pesquisam a temática contemplam as questões relacionadas a este profissional? Como a legislação publicada pelo governo paulista caracteriza o perfil do profissional? E os concursos públicos aos quais o diretor foi submetido para assumir seu cargo: quais expectativas eles apresentam em relação ao perfil? Considerando os limites do artigo científico, temos o objetivo de analisar o (s) possível (is) perfil (is) do diretor de escola pública paulista, problematizando a literatura da área, os concursos públicos e as diretrizes da política, ambos estaduais, em uma perspectiva histórica. Para a construção do texto, trabalhamos com o "perfil" entendido como aspectos que dizem respeito à formação e atuação do profissional diretor de escola.

Analisaremos o(s) perfil(s) dos diretor(es) de escola pública paulista a partir de três âmbitos que se constituem nas seções principais deste artigo. Na primeira, realizamos levantamento e análise de obras de autores clássicos da Administração escolar, produzidas a partir da década de 1950. Na segunda, destacamos as expectativas de órgãos centrais do ensino do estado de São Paulo em relação à atuação do diretor de escola e o pensamento administrativo que, supostamente, orientou e/ou orienta a administração das escolas públicas paulistas, a partir dos editais de concursos públicos para diretor de escola. Na terceira seção, realizamos um recorte da legislação do estado de São Paulo, que de forma direta ou indireta, contempla a atuação do diretor de escola (entre os anos 1980 e 2000), procurando identificar, também, as expectativas do estado em relação ao profissional. Ao final, tensionamos os diferentes âmbitos analisados e lançamos algumas questões que poderão subsidiar novas pesquisas em relação à temática.

\section{Publicações da área: do diretor ao gestor escolar}

Mediante o resgate histórico dos principais trabalhos teóricos produzidos no campo da Administração da educação no Brasil, observamos que o estudo sistemático na área constitui um fenômeno relativamente recente e que durante muito tempo baseou-se, quase exclusivamente, na Teoria Geral da Administração. 
Nosso campo empírico para analisar as perspectivas presentes nas publicações da área quanto ao perfil do diretor escolar foi constituído a partir do levantamento, por década, das principais obras publicadas, de autoria única, sobre a teoria da Administração escolar no Brasil. Para isto, tomamos como ponto de partida os anos 1950, momento em que se deu, no Brasil, um amplo debate entre os professores de Administração escolar sobre a possibilidade de constituírem uma Associação que discutisse o tema e produzisse conhecimento para ser ensinado nos cursos que formavam, à época, o administrador escolar. Entre os professores que participaram deste movimento, estão José Querino Ribeiro e Anísio Teixeira, dos quais foram tomados como referência, respectivamente, o livro lançado em 1952 para ser adotado nas aulas ministradas na Universidade de São Paulo e o artigo escrito para o primeiro Caderno de Administração Escolar, publicação da Associação Nacional de Professores de Administração Escolar (ANPAE), fundada em 1961, por diversos professores de Administração escolar do Brasil.

Ribeiro (1952, p. 131) argumentava que a atividade diretiva, pela sua complexidade, requer formação específica e, apesar de não afirmar que o diretor de escola precisa, necessariamente, ter algum tempo de experiência docente, supõe que para dar assistência à execução e orientar os trabalhos escolares "um diretor tem uma visão de conjunto melhor que o professor" e "uma experiência maior ou, pelo menos, equivalente à do professor".

Teixeira (1968, p. 14), por sua vez, sustentava que a administração escolar, por ser uma função subordinada à tarefa educativa, pode ser exercida apenas por educadores, os quais precisam ser formados com o mesmo padrão de excelência com que são formados os médicos. Importa registrar, no entanto, que para esse pensador, a Administração escolar tem natureza e funções específicas e, por isso, não pode ser equiparada à Administração de empresas. Em suas palavras, "embora alguma coisa possa ser aprendida pelo administrador escolar de toda a complexa ciência do administrador de empresa de bens materiais de consumo, o espírito de uma e outra administração são de certo modo até opostos". (TEIXEIRA, 1968, p. 15).

Dos anos 1970, tomamos como referência a primeira edição do livro de Alonso (1976), pois se trata de uma das principais publicações da década, referenciada para concurso de diretor de escola no estado de São Paulo, o qual contempla o papel do diretor da escola de $1^{\circ} \mathrm{e} 2^{\circ}$ graus, em uma perspectiva sistêmica. Cabe ressaltar que tanto Ribeiro (1952) quanto Alonso (1976) trabalharam embasados na administração empresarial, adaptando-a a escola pública. O primeiro teve a intenção de realizar uma introdução ao assunto, delineando princípios, fundamentos e objetivos da administração escolar, a partir de abordagem taylorista-fordista, e a segunda teve o objetivo de centrar-se na função do diretor na Administração escolar, subsidiando-se na teoria sistêmica, com seus avanços em relação às teorias anteriores da administração empresarial. Alonso (1976) prossegue, portanto, com o raciocínio que equipara a empresa à escola e afirma que a função administrativa apresenta natureza genérica, na medida em que se trata de uma função comum a todas as organizações. A autora defende que a atividade administrativa deve promover o ajustamento dos fatores internos e externos do sistema escolar para que ele se mantenha em equilíbrio. Cabe ao admi- 
nistrador, nesta perspectiva, ser influente na tomada de decisões, justificar suas ações e proposições junto aos órgãos superiores e deles trazer informações para interpretá-las e aplicá-las no contexto escolar. Neste sentido, a função do diretor e/ou administrador escolar "não é mais uma função logística, isto é, de mobilização de recursos, mas sim uma função estratégica, ou seja, de condicionador de reações daqueles que serão afetados por certos objetivos e ações". (ALONSO, 1976, p. 154). No que respeita à formação do administrador escolar, a autora, recorrendo a Walton (1959), considera necessário que este profissional seja um educador e não esteja adstrito às tarefas puramente administrativas.

Embora haja muitas e ricas publicações de autores que criticam a produção teórica anterior a partir do final da década de 1970 e nos anos 1980, tomamos a tese de doutorado de Paro, publicada em livro em 1986, para dela extrairmos os elementos teóricos que rompem com o paradigma empresarial. Neste livro, o autor caracteriza o modo de produção da sociedade capitalista para negar sua disseminação no âmbito da escola, a qual, em sua concepção, tem um potencial de transformação social.

A maioria dos trabalhos teóricos produzidos no âmbito da Administração da educação no país, nesse período questionou a utilização do paradigma empresarial como fundamento da prática administrativa escolar mediante o argumento de que a escola, por apresentar objetivos distintos da empresa, necessitaria de uma elaboração teórica própria capaz de abranger seus problemas e sua especificidade. Outro traço marcante, presente nesses estudos, é a oposição à administração centralizada e a defesa da participação dos diferentes segmentos escolares nos processos decisórios da escola. Devido ao fato de concentrarem as atenções nas finalidades da atividade administrativa, os trabalhos teóricos, de certa maneira, deixam em segundo plano a discussão acerca da formação do diretor de escola, mas ressaltam a necessidade de que ele compreenda criticamente as funções da escola e suas múltiplas dimensões e relações com a sociedade (PARO, 1986; ARROYO, 1979).

É possível dizermos que estes trabalhos, principalmente o de Paro (1986), não apenas questionam os objetivos diferentes presentes em uma e em outra administração (escolar e empresarial) como radicalizam a diferença, uma vez que, fundamentando-se na teoria marxista, opõem o processo de produção pedagógico ao processo de produção fabril, admitindo a não generalização do modo de produção capitalista na escola.

Nos anos 1990, última década em que pudemos localizar livros de autoria única, ao contrário dos anos anteriores, identificamos perspectivas divergentes de autores que, além de produzirem teoria, ocuparam cargos na gestão de sistemas escolares. Tratam-se de Guiomar Namo de Mello, que ocupou a Secretaria de Educação do Município de São Paulo, em meados dos anos 1980, e de Paulo Freire, que ocupou o mesmo cargo na gestão de Luiza Erundina, do Partido dos Trabalhadores (PT), na prefeitura do município. O livro de Mello (1993) é uma junção de artigos apresentados internacionalmente e o de Freire (1991) é uma coletânea de entrevistas concedidas a jornais e pesquisadores nos dois primeiros anos de sua gestão. 
Embora alguns estudos no campo da Administração da educação, publicados no final da década de 1970 e nos anos 1980, tenham iniciado um movimento que se desloca do paradigma da empresa para o paradigma pautado na especificidade da escola, ${ }^{1}$ a partir dos anos 1990, é possível notar o ressurgimento de estudos baseados na perspectiva empresarial. Baseada nessa perspectiva, Mello (1993) parece preocupar-se com o atendimento de interesses essencialmente econômicos, ao condicionar o desenvolvimento do país e sua inserção em âmbito internacional à formação do capital humano via educação escolar. Perspectivas opostas, no entanto, conviveram, teórica e praticamente, com a referida proposta. Freire (1991), por exemplo, defendeu, em sua gestão como secretário de educação do município de São Paulo, a escola popular, "séria e alegre", a partir de práticas democráticas de tomada de decisão coletiva, como os conselhos escolares. Para ele, o conselho de escola se efetivaria com o favorecimento de experiências e condições para seu desenvolvimento. Assim, incorporada ao cotidiano das escolas, a gestão democrática teria vida mais intensa, o que abriria caminho para o entusiasmo entre todos os envolvidos no processo educacional.

Em relação à produção teórica mais recente, no âmbito da Administração da educação no Brasil, principalmente a partir dos anos 2000, é possível perceber dicotomia da produção teórica. Por um lado, os estudos apresentam uma crescente tendência de se diluir nos assuntos de Política Educacional e a maioria das publicações passa a ser organizada na forma de coletânea, não apresentando estudos substanciais voltados para a teoria administrativa escolar. De um modo geral, os livros e artigos produzidos, sob esta tendência, discutem questões relacionadas à autonomia, participação, trabalho coletivo e têm como foco a democratização da educação e da gestão. ${ }^{2}$ Por outro lado, há a revitalização da perspectiva empresarial nos assuntos da Administração escolar e, nesta perspectiva, o diretor escolar se apresenta como o profissional responsável pelo funcionamento da escola, o líder de toda comunidade acadêmica, aquele que busca a eficiência de seus resultados (LÜCK, 2000).

A tendência dos anos 1990 de vínculo entre desenvolvimento econômico e educação, "cidadania e competitividade", propagou a ideia de que os problemas da educação deviam-se, exclusivamente, à ineficiência da gestão (MELLO, 1993) e que, portanto, uma gestão eficaz seria responsável pela qualidade da educação escolar. Neste sentido, o foco recaiu sobre a gestão da escola, em uma perspectiva empresarial novamente, disseminando práticas gerencialistas nos âmbitos estaduais, municipais e escolares, como a competitividade entre escolas, a meritocracia, o foco em resultados, entre outros. Se, por um lado, as diretrizes políticas voltadas ao setor educacional têm essas marcas, por outro lado, a produção teórica em Administração escolar, produzida em forma de coletâneas e artigos, se opõe a tais práticas, mas não constroem alternativas teóricas que contribuam para sua superação.

Vale destacar que a disseminação do gerencialismo, no setor educacional, tem sido amplamente criticada por pesquisadores internacionais e nacionais. De acordo com Ball (2006), tal abordagem postula que o sucesso competitivo pode ser alcançado pela restrição dos sistemas de controle, pela motivação das pessoas em produzir com "qualidade" e pelo esforço em busca da "excelência", induzindo a criação nas escolas de formas organizacionais predominantes no setor privado. Silva Jr. (2002) afirma 
que a crescente mercadorização dos critérios de gestão educacional faz prevalecer a lógica do mercado educacional sobre a lógica do direito à educação, privilegiando a "criatividade gerencial" inata ou construída de um bom "gestor" e remetendo a outras instâncias a preocupação com a qualidade do processo de ensino que se desenvolve no interior das escolas.

Em síntese, considerando nosso levantamento empírico e a análise dos livros publicados por década que trataram da Administração da educação no Brasil, é possível evidenciar alguns aspectos interessantes a respeito do perfil do diretor escolar. Os estudos que contemplaram o assunto, até meados dos anos 1970, fizeram-no individualizando a função - "administrador escolar, diretor escolar" - sob o respaldo teórico da Administração empresarial, com exceção de Anísio Teixeira, que também aborda a função do "administrador escolar", mas considera tal função completamente distinta da exercida pelo administrador empresarial (manager). Com a mudança paradigmática, os autores passam a focalizar os assuntos da escola, da especificidade de sua administração, não mais centrados na figura do diretor/administrador. Os anos 1990 convivem com dualidade no pensamento administrativo escolar: por um lado, a continuidade de sua especificidade e a valorização da gestão democrática e, por outro, a revitalização da perspectiva empresarial. A partir da década seguinte, observa-se um arrefecimento dos estudos teóricos da Administração escolar, que são contemplados pelos autores de forma diluída nos assuntos de Política educacional, com foco na gestão democrática, autonomia e participação. Entretanto, de forma concomitante, há a continuidade daqueles estudos embasados na teoria administrativa empresarial, mas, neste momento, desprovidos daquelas preocupações iniciais (dos anos 1960) com os objetivos estritamente educacionais.

A questão que permeia a próxima seção é: em que medida tal pensamento refletiu-se nos editais e nas provas dos concursos ao longo dos anos de existência?

\section{O que o estado de São Paulo esperava e/ou espera de um diretor de escola?}

Com o intuito de identificar as expectativas de órgãos centrais do ensino de São Paulo em relação à atuação do diretor de escola e as mudanças que tais expectativas vão sofrendo ao longo do tempo, bem como o pensamento administrativo que, supostamente, orientou e/ou orienta a administração das escolas públicas paulistas, realizamos o levantamento e a análise dos editais e das provas dos concursos públicos para provimento desse cargo, realizados no estado a partir do final da década de $1970{ }^{3}$

No período delimitado para o estudo, foram promovidos seis concursos na rede estadual de ensino paulista. Seus respectivos editais foram localizados no site da Imprensa Oficial de São Paulo ${ }^{4}$ e as provas foram encontradas no Departamento de Recursos Humanos (DRHU) da Secretaria de Educação do Estado de São Paulo. A análise dos materiais coletados permitiu identificar características comuns entre os concursos realizados, em duplas sequenciais. Em linhas gerais, é possível afirmar: 
- Nos concursos realizados em 1979 e 1982, os princípios para fundamentar a atividade administrativa realizada nas escolas foram buscados no arcabouço teórico da administração empresarial (COOMBS, 1976; ALONSO, 1976; GRIFFITHS, 1977; KIMBROUGH, 1977; RIBEIRO, 1978; BEEBY, 1973; HERSEY; BLANCHARD, 1976; SERGIOVANNI; CARVER, 1976) (destaques nossos) e o diretor foi identificado como aquele profissional que ocuparia posição de especial importância na escola, cuja função seria coordenar o trabalho da equipe escolar garantindo a consecução dos objetivos educacionais e o cumprimento das normas e diretrizes produzidas e determinadas por instâncias superiores do ensino.

- Já os concursos promovidos em 1988 e 1998, acompanhando a transição paradigmática em curso no campo da Administração escolar no país, listaram, nas bibliografias de referência, publicações que questionaram a utilização da perspectiva empresarial como fundamento da prática administrativa realizada nas escolas e apontaram a necessidade de encontrar uma base teórica específica para tal atividade (PARO, 1986; SILVA JR, 1986; FÉLIX, 1984). Observamos também uma mudança na maneira de se conceber o papel do diretor, que deixa de ser considerado a figura central, devendo desenvolver seu trabalho de forma mais articulada de modo a garantir que todos os envolvidos no processo educativo participem das decisões que dizem respeito à organização e ao funcionamento da escola.

- Os concursos realizados em 2001 e 2007, por sua vez, revelaram que em lugar da construção de um paradigma alternativo para a Administração escolar houve uma dispersão teórica na área, bem como o resgate, com novos argumentos, da gerência empresarial na educação (MELLO, 1993; MOTTA, 1996; SCHNECKENBERG, 2000; VIEIRA; ALMEIDA; ALON$\mathrm{SO}, 2003$ ) (destaque nosso). O diretor, agora gestor, também parece ganhar um novo destaque, devendo reunir características que lhes permitam articular e executar as políticas educacionais no âmbito da escola, pautadas, sobretudo, no desenvolvimento de uma cultura centralizada no desempenho.

Cabe assinalar, ainda, que nos dois últimos processos de seleção de diretores escolares, promovidos pela rede estadual de ensino paulista, foram introduzidas algumas mudanças nos requisitos para a inscrição. A formação específica em Administração escolar deixou de ser uma exigência para os profissionais, graduados em Pedagogia e aqueles com outro tipo de graduação, mas que tivessem experiência de oito anos no magistério e fossem mestres ou doutores na área de Educação, também poderiam se inscrever. ${ }^{5} \mathrm{~A}$ ausência da formação específica para os pedagogos e a possibilidade de que candidatos com diferentes formações prestem o concurso e assumam o cargo diretivo de uma escola, no entanto, trazem alguns desafios para o estabelecimento de uma identidade profissional e, principalmente, para a atuação do futuro diretor de escola.

No quadro geral do país, o preparo do profissional que deverá assumir funções na direção escolar, independentemente da forma de provimento do cargo, tem sido realizado nos cursos de formação continuada. Geralmente organizados por órgãos centrais do ensino, eles têm seus programas inspirados no gerencialismo empresarial 
e privilegiam os aspectos tecnocráticos da função do diretor de escola em detrimento de questões sociais e educacionais mais amplas que possibilitem uma melhor compreensão das funções da escola e de suas múltiplas dimensões e relações com a sociedade.

Segundo Oliveira (2008), nos cursos destinados à formação de diretores que já estão em exercício, o profissional responsável pela direção é, novamente, colocado no centro da estrutura de poder da escola, algo similar ao que fora defendido, em outros tempos, pelos precursores da Administração Científica do Trabalho na gestão escolar. Além disso, tais treinamentos esvaziam de conteúdo crítico e analítico as atitudes do diretor, atribuindo-lhe o papel de gerente de um negócio que precisa viabilizar-se: a escola. ${ }^{6}$

A ausência de formação inicial consistente, que propicie ao diretor de escola condições de proceder à análise crítica e contextualizada da educação e do ensino, faz com que esse profissional torne-se cada vez mais vulnerável às determinações e/ou intervenções de instâncias superiores do ensino na sua formação e, consequentemente, na sua atuação.

A trajetória do conhecimento em Administração escolar refletiu diretamente nos concursos públicos para o diretor de escola no estado de São Paulo, com o predomínio, nos últimos anos, da perspectiva empresarial. Este fato, somado à ausência do requisito da formação específica e à necessidade de cursar a formação continuada, embasada, sobretudo, na legislação que norteia as ações da Secretaria de Educação do estado de São Paulo, podem contribuir, significativamente, para determinar um perfil do diretor de escola paulista.

\section{Legislação estadual: implicações para a atuação do diretor de escola}

Desenvolvemos esta seção realizando um recorte da legislação publicada pelo estado de São Paulo, que foi possível devido à vasta coleta de dados realizada para a consecução da pesquisa integrada. Sendo assim, a análise está baseada no Estatuto do Magistério Paulista (1985), em leis que introduzem a avaliação em larga escala no estado (anos 1990 e 2000) e que dizem respeito, especificamente, ao perfil do profissional, precisamente referenciadas durante a análise.

Adiantando-se em relação à publicação da Constituição Federal (BRASIL, 1988) e à Lei de Diretrizes e Bases da Educação Nacional (BRASIL, 1996), o estado de São Paulo promulgou o Estatuto do Magistério Paulista (Lei Complementar n. 444/1985), que trata, em suas disposições finais, do Conselho de Escola como órgão deliberativo da organização escolar. Segundo Pinto (1999, p. 222), sua aprovação em Lei é fruto de negociação na Assembleia Legislativa, uma vez que os diretores se manifestaram contrários, "pais e alunos estiveram ausentes das discussões, e a garantia do caráter deliberativo e composição paritária entre comunidade intra e extraescolar só foi possível em virtude da pressão da entidade representativa dos professores da Associação dos Professores do Ensino Oficial do Estado de São Paulo (APEOESP)”. $\mathrm{O}$ autor declara ainda que, à conquista, deve-se acrescentar o fato de André Franco 
Montoro estar no início de sua gestão, no governo paulista, e ter sido eleito graças a propostas de descentralização e democratização da escola, alimentadas, sem dúvida, pelo "clima geral de euforia e participação marcado pela luta por redemocratização, com o ocaso do regime militar" (PINTO, 1999, p. 222).

O Estatuto dispõe sobre a composição do Conselho de Escola da seguinte forma: $40 \%$ docentes; $25 \%$ de pais de alunos; $25 \%$ de alunos; $5 \%$ de especialistas (exceto diretor) e $5 \%$ de demais funcionários, devendo ser presidido pelo diretor de escola. O órgão colegiado passa a ter função deliberativa, deve reunir-se, ordinariamente, duas vezes no semestre e, quando necessário, por convocação do diretor ou 1/3 dos seus membros. ${ }^{7}$ Foram inúmeros avanços propostos pela Lei: a participação efetiva da comunidade na escola, na tomada de decisão sobre suas diretrizes e metas, projetos, prioridades, elaboração de regimento escolar, apreciação de relatórios e avaliação da escola; a escolha dos membros pelos seus pares; a clareza e transparência das decisões por meio de registros em atas tornadas públicas.

No entanto, alguns autores (PINTO, 1999; PARO, 1999) indicam que, depois de mais de uma década, o dispositivo legal não conseguiu alterar a forma de organização da escola pública estadual, em virtude de estar fundamentalmente ancorada na hierarquia e na autoridade do diretor de escola. Estes autores alegam que se tratou de uma medida isolada, "descolado de uma política mais ampla e séria de democratização da escola" e que, para a reversão de tal quadro, "é preciso uma nova ética que desautorize a atual configuração autoritária da escola” (PARO, 1999, p. 210).

Apesar das conquistas legais no sentido de incentivar, na escola, a gestão democrática e a participação da comunidade na tomada de decisão, a organização do trabalho circunscrita na figura do diretor (tal como aquela perspectiva delineada pelos autores entre os anos 1960 e 1970) predomina e triunfa sobre outras concepções. A legislação contemplada valorizava e incentivava a participação, autonomia e gestão democrática, o que contribui para se vislumbrar uma perspectiva mais afinada com a abordagem progressista de Administração escolar (PARO, 1986; FREIRE, 1991).

Em meados dos anos 1990, assume o governo paulista o Partido da Social Democracia Brasileira (PSDB), que toma várias medidas por meio da Secretaria de Educação do Estado, entre as quais se destacam a municipalização, a progressão continuada e o Sistema de Avaliação do Rendimento da Educação do Estado de São Paulo (SARESP). Nesse período, foram emitidas diretrizes para as escolas estaduais sob o discurso de fortalecimento da autonomia, cuja máxima se encontra na política de Progressão Continuada e suas contradições: uma vez que a repetência foi eliminada no interior dos ciclos, foi necessário exercer controle sobre desenvolvimento do processo de aprendizagem dos alunos, ano a ano (SEE,1996). Em lugar de construções de práticas de avaliação interna, criou-se o SARESP, com o objetivo de ser um mecanismo de aferição para verificar, nas escolas, os processos pedagógicos frente a essas mudanças.

Apesar das modificações do SARESP durante suas edições, seus objetivos não se distanciaram dos iniciais, apontando sempre um caráter gerencial embasado na possibilidade de mensuração do desempenho e replanejamento pedagógico em função 
de resultados, visando à melhoria da qualidade de ensino. ${ }^{8} \mathrm{~A}$ avaliação do SARESP chega às escolas, completando 16 anos em 2013. Ao sistema de avaliação foi acrescentada a adoção da política de bonificação aos professores, tendo em vista os resultados atingidos.

Além de ser um mecanismo de aferição do trabalho administrativo e pedagógico das unidades, o sistema paulista de avaliação em larga escala configura-se em um elemento indutor de políticas públicas educacionais que priorizam a meritocracia e a equidade dos processos escolares face aos indicadores estipulados pelo governo.

Dada à preocupação com o alcance de resultados de aprendizagem, no bojo dessas medidas, são publicados: a Resolução SE n. 70/2010 e o Decreto n.57.141/2011, que tratam, respectivamente, dos perfis profissionais, competências e habilidades requeridos dos educadores da rede pública estadual e da reorganização da Secretaria de Educação do Estado de São Paulo. Particularmente, na Seção X do Capítulo X, o decreto estadual aborda as atribuições dos diretores de escolas sob a condição de "gestores escolares".

Ambos causam certo desconforto quando avaliados em confronto com as conquistas legais dos anos 1980, uma vez que neles predomina o uso de termos empresariais, cujo foco incide na hierarquia e na individualização das tarefas da organização do trabalho escolar na figura do diretor (agora tratado como gestor).

O governo paulista determina cinco dimensões de competências para a atuação do diretor de escola, assim discriminadas: de resultados educacionais do processo ensino-aprendizagem; participativa; pedagógica; dos recursos humanos; dos recursos físicos e financeiros.

Apenas uma vez o Decreto estadual discorre a respeito da gestão democrática, porém, a relaciona com "princípios de liderança, mediação e gestão de conflitos", utilizando-se de termos amplamente empregados na Administração empresarial contemporânea. Quando contempla participação, o documento acentua que o diretor deve "estimular o estabelecimento de parcerias com vistas à otimização de recursos disponíveis na comunidade". A sexta competência elencada para o diretor de escola - "compreender a visão contemporânea de gestão escolar vinculada a resultados" - articula-se a esse discurso, na medida em que corrobora a noção de escola equiparada à empresa.

O Decreto n. 57.141/2011 dedica ainda os artigos 94 e 106 para atribuir as competências comuns "aos chefes de gabinete e aos demais dirigentes de unidades até o nível hierárquico de serviço, aos dirigentes regionais de ensino, aos diretores de escola e aos responsáveis por unidades de nível equivalente, em suas respectivas áreas de atuação". Neste sentido, articuladas às atividades gerais e às do Sistema de Administração de Pessoal, predominam verbos como "cumprir", "submeter", "encaminhar", "zelar", "fiscalizar", e substantivos/adjetivos como "autoridades superiores", "subordinados", "superiores", "hierárquicos", "resultados". 
Mediante a análise da legislação estadual, é possível observar a introdução de um novo paradigma de gestão das escolas paulistas nas últimas décadas. Conforme anunciado anteriormente, fundamentado na perspectiva gerencialista, tal paradigma de gestão centra-se, sobretudo, na figura do diretor escolar e busca transformar as estruturas organizacionais das escolas em regimes empresariais competitivos. Nesses regimes, são colocadas em prática novas formas de vigilância e monitoramento, como os sistemas de avaliação e a comparação de resultados.

\section{Considerações finais}

O objetivo principal deste texto foi analisar se, a partir do estudo e do tensionamento da produção da área da Administração escolar, das legislações publicadas pelo governo paulista e dos concursos públicos para o cargo do diretor de escola, é possível identificar um perfil deste profissional, entendido como, entre outros aspectos, sua formação e sua atuação.

A análise nos permite afirmar que a maioria dos pioneiros que abordou o assunto, entre os anos 1960 e meados dos anos 1970, apoiou-se na Administração de empresas, mas todos afirmaram que era imprescindível a formação e a atuação de base, ou seja, antes de assumir o cargo, o diretor precisava ser educador. Embasados na empresa, estes autores conceberam o diretor como executivo na unidade escolar, líder no sentido de motivar o alcance de objetivos postos fora e acima de sua escola, e autoridade hierarquicamente constituída e responsável pelo progresso da empresa escolar. Os autores da década de 1980, por priorizarem a discussão em torno dos fins da Administração escolar e de sua especificidade, marcando a mudança paradigmática da área, não focalizaram a formação do diretor, mas, assim como os autores anteriores, sugerem que esse profissional precisa ser educador, ou seja, ter formação na área de educação. Estes autores também contribuíram significativamente para trazer à discussão a importância dos aspectos políticos em detrimento dos técnicos na formação do educador, especificamente, do diretor de escola. Nos anos mais recentes, há diminuição da produção teórica da área que faça jus ao que foi indicado como fundamental na década de 1980: construção de um corpo teórico próprio para a Administração escolar. O que predomina na área são autores que organizam livros em formas de coletânea que discutem assuntos de Administração, diluídos nos de Política educacional, e livros de autores únicos que retomam a defesa da Administração de empresas na Administração escolar.

As características desta trajetória refletiram diretamente na construção dos concursos públicos, aos quais os profissionais da educação foram submetidos para ocuparem o cargo de diretor de escola. Cabe-nos ressaltar, principalmente, os autores elencados nos concursos de 1988 e 1998, que questionam a adoção da Administração empresarial na escola, e os autores dos últimos concursos (2001 e 2007), que retomam a gerência empresarial nas questões educacionais. Além disso, ressaltamos, na análise, que no último edital não há mais exigência da formação em Pedagogia e em Administração escolar para prestar tais concursos públicos.

Estas constatações, somadas ao estudo da legislação paulista, permitem-nos afirmar que, apesar do avanço dos anos 1980 (e não da década perdida, como expli- 
citada por outros autores), sobremaneira no que diz respeito à negação da Administração empresarial e ao incentivo para a construção de um corpo teórico próprio para a Administração escolar, o que predomina é a ausência de formação inicial sólida do diretor de escola e uma atuação baseada no "manager", aquele executivo responsável pelo alcance de resultados predeterminados e que, como na empresa, precisa apenas motivar seus "subordinados" para a consecução das metas.

Os avanços conquistados que dizem respeito às vivências democráticas, na escola, encontram barreiras reais quando o diretor concursado é submetido aos cursos de formação continuada e ao cumprimento da legislação, que determinam um perfil gerencial esvaziado de outras possibilidades por não dialogar com uma formação inicial fortalecida e alternativa ao que recebe, quase diariamente, das instâncias superiores.

\section{Referências}

ALONSO, M. O papel do diretor na administração escolar. São Paulo: Difel, 1976.

BRASIL. Constituição da República Federativa do Brasil de 1988. Disponível em: <http:// www.planalto.gov.br/ccivil_03/Constituicao/Constituicao.htm>. Acesso em: 09 mar. 2012.

ARROYO, M. G.. Administração da educação: poder e participação. Educação \& Sociedade, v. 1, n. 2, p. 36-46, jan. 1979.

BALL, S. Sociologia das políticas educacionais e pesquisa crítico-social: uma revisão pessoal das políticas educacionais e da pesquisa em política educacional. Currículo sem fronteiras, vol. 6, n. 2, p. 10-32, jul/dez. 2006.

BEEBY, C. E. O planejamento e o administrador educacional. Tradução de Leonidas Gontijo de Carvalho. Cadernos de Pesquisa, São Paulo, Fundação Carlos Chagas, n. 7, p. 74-91, jun. 1973.

BRASIL. Lei $\mathbf{N}^{\circ}$ 9.394, de 20 de dezembro de 1996. Portal do Ministério da Educação. Disponível em: <http://www.planalto.gov.br/ccivil_03/Leis/L9394.htm〉. Acesso em: 09 mar. 2012.

COOMBS, P. H. A crise mundial da educação: uma análise de sistemas. São Paulo: Editora Perspectiva, 1976.

FÉLIX, M. de F. C.. Administração escolar: problema educativo ou empresarial? São Paulo: Cortez: Autores Associados, 1984.

FERREIRA, N. S. C.; AGUIAR, M. A. da S. (Orgs.). Gestão da educação: impasses, perspectivas e compromissos. São Paulo: Cortez, 2001.

FREIRE, P. A educação na cidade. 7a ed. São Paulo: Cortez, 1991.

GRIFFITHS, D. E. Teoria da administração escolar. Tradução de José Augusto Dias. São Paulo: Editora Nacional, 1977.

HERSEY, P.; BLANCHARD, K. H. Psicologia para administradores de empresas: a utilização de recursos humanos. Tradução: Dante Moreira Leite. São Paulo: EPU: Rio de Janeiro: Fundação Nacional de Material Escolar, 1976.

KIMBROUGH, R. B. Princípios e métodos de administração escolar. Tradução: Loyde Amália Faustini e Helena Maria Bicalho Behar. São Paulo: Saraiva, 1977.

LIBÂNEO, J. C.; OLIVEIRA, J. F. de; TOSCHI, M. S. Educação escolar: políticas, estrutura e organização. (Orgs.). 2. ed. São Paulo: Cortez, 2005. 
MELLO, G. N. de. Cidadania e competitividade. Desafios educacionais do terceiro milênio. São Paulo: Cortez, 1993.

MOTTA, P. R. Gestão contemporânea: a ciência e a arte de ser dirigente. Rio de Janeiro: Record, 1996.

OLIVEIRA, D. A. Mudanças na organização e na gestão do trabalho na escola. In: OLIVEIRA, D. A.; ROSAR, M. de F. F. (Orgs.). Política e gestão da educação. 2. ed. Belo Horizonte: Autêntica, 2008.

OLIVEIRA, D. A.; ROSAR, M. de F. F.. (Orgs.). Política e gestão da educação. 2. ed. Belo Horizonte: Autêntica, 2008.

PARO, V. H. Administração escolar: introdução crítica. São Paulo: Cortez: Autores Associados, 1986.

PINTO, J. M. de R. O paradoxo do Conselho de escola. In: BICUDO, M. A. V.; SILVA JR. C. A. (Orgs.). Formação do educador: organização da escola e do trabalho pedagógico. Vol. 3. São Paulo: Editora UNESP, 1999. (Seminários \& Debates). P. 219-248.

RIBEIRO, J. Q. Ensaio de uma teoria da administração escolar. São Paulo: FFCL/USP, 1952. (Administração escolar e educação comparada; boletim 158).

Introdução à Administração Escolar: alguns pontos de vista. Cadernos de Administração Escolar. n. 2. Salvador: ANPAE. 1968.

SÃO PAULO. Lei complementar n. 444, de 27 de dezembro de 1985.Dispõe sobre o Estatuto do Magistério Paulista e dá providên $\neg$ cias correlatas. São Paulo: 1986. Vol. 96, n. 61. Disponível em: <http://siau.edunet.sp.go v.br/ItemLise/arquivos/n otas / lei com p 444_85.htm>.Acesso em: 09 mar. 2012.

SÃO PAULO. Resolução SE No 27, de 29 de março de 1996. Dispõe sobre o Sistema de Avaliação de Rendimento Escolar do Estado de São Paulo. Disponível em: <http://lise.edunet. sp.gov.br/paglei/resolucoes/27_1996.htm> Acesso em: 09 mar. 2012.

SCHNECKENBERG, M. A relação entre política pública de reforma educacional e a gestão do cotidiano escolar. Em aberto, Brasília, v. 7, n. 72, p. 113-124, fev./jun. 2000.

SERGIOVANNI, T. J.; CARVER, F. D. O novo executivo escolar: uma teoria da administração. Tradução: Loyde Amália Faustini e Martha FaustiniEgg. São Paulo: EPU, 1976.

SILVA JR, C. A. da. Organização do trabalho na escola: a prática existente e a teoria necessária. Cadernos de Pesquisa, São Paulo, Fundação Carlos Chagas, n.59, p.73-76, nov./1986.

SILVA JR, C. A. da. O espaço da administração no tempo da gestão. In: MACHADO, L. M.; FERREIRA, N. S. C. (Orgs.). Política e gestão da educação: dois olhares. Rio de Janeiro: DP\&A, 2002.

TEIXEIRA, A. Natureza e função da Administração Escolar. In: Administração Escolar: Edição comemorativa do I Simpósio Interamericano de Administração Escolar. Salvador: ANPAE, p. 1-47, 1968.

VIEIRA, A. T.; ALMEIDA, M.E. B. de; ALONSO, M. (Orgs.). Gestão educacional e tecnologia. São Paulo: Avercamp, 2003.

WALTON, J. Administration and Policy-Marking in Education. Baltimore: The Johns Hopking Press, 1959. 
${ }^{1}$ Além dos trabalhos de Arroyo (1979) e Paro (1986), colaboraram para tal movimento os estudos Félix (1984) e Zung (1984).

${ }^{2}$ Como exemplo, podemos citar: Ferreira e Aguiar (2001), Libâneo, Oliveira e Toschi (2005), Oliveira e Rosar (2008).

${ }^{3}$ Este objetivo, especificamente, foi contemplado mediante o desenvolvimento de pesquisa de mestrado que também contou com o apoio financeiro da Fundação de Amparo à Pesquisa do Estado de São Paulo (FAPESP) e resultou na dissertação intitulada "Formação e função do diretor de escola: análise a partir dos concursos públicos realizados na rede estadual de ensino de São Paulo (1979- 2007)”.

${ }^{4} \mathrm{O}$ endereço do site é www.imprensaoficial.com.br.

${ }^{5}$ No concurso realizado no ano de 2007, puderam efetuar a inscrição também profissionais com pós-graduação em nível de especialização em Gestão Escolar de, no mínimo, 800 horas.

${ }^{6}$ Abdian e Hernandes (2013) apresentam a construção de formação continuada alternativa aos cursos em andamento na qual predominou o desenvolvimento de prática escolar democrática.

${ }^{7}$ Segundo Pinto (1999), o Conselho de Escola tem sua origem nas antigas congregações reguladas pelo Decreto n. 22.036/1953, que foram substituídas pelos Conselhos de Professores mediante o Decreto n. 45. 159/1965. O autor acrescenta que o Conselho de Escola de caráter consultivo data do regimento comum das escolas estaduais (Decreto n. 10.623/1977); transformou-se em órgão deliberativo pela promulgação da Lei Complementar n. 375/1984. A Lei Complementar n. 444/1985 prescreveu sua forma atual.

${ }^{8}$ Nesse período $(1996$ - 2011) o governo do estado permaneceu sobre as diretrizes governamentais do (PSDB).

* Doutoranda da Universidade Estadual Paulista Júlio de Mesquita Filho, Marília, São Paulo, Brasil.

** Professora Doutora daUniversidade Estadual Paulista Júlio de Mesquita Filho, Marília, São Paulo, Brasil.

\section{Correspondência}

Viviani Fernanda Hojas - Universidade Estadual Paulista Júlio de Mesquita Filho, Faculdade de Filosofia e Ciências - Campus de Marília. Av. Hygino Muzzi Filho, 737, Campus Universitário. CEP: 17525-900

- Marilia, São Paulo, Brasil.

E-mail:vihojas@hotmail.com - graziela.maia@gmail.com

Recebido em 10 de abril de 2013

Aprovado em 17 de novembro de 2014 